\title{
ENVERDECIMIENTO DE LAS CORTES \\ LATINOAMERICANAS: ÚLTIMOS AVANCES \\ JURISPRUDENCIALES
}

\section{ENVERDECIMENTO DOS TRIBUNAIS DA AMÉRICA LATINA: ÚLTIMOS AVANÇOS JURISPRUDENCIAIS}

THE "GREENING" OF THE LATIN AMERICAN COURTS: LATEST JURISPRUDENTIAL ADVANCES

\section{Mario Peña Chacón ${ }^{1}$}

Licença CC BY:

Artigo distribuído sob os termos Creative Commons, permite uso e distribuição irrestrita em qualquer meio desde que $o$ autor credite a fonte original.

\begin{abstract}
Resumen: Es objeto de análisis del presente artículo, son las sentencias sobre cuestiones ambientales de las altas cortes de países como Argentina, Brasil, Colombia, México y Costa Rica. Las sentencias analizadas muestran las últimas tendencias de la Justicia Ecológica a nivel regional, entre ellas: el cambio en el paradigma jurídico que rige la relación hombre-naturaleza; el papel preponderante del derecho internacional de los derechos humanos y del derecho constitucional en la protección ambiental; la aplicación del enfoque basado en derechos y de ecologización de los derechos humanos; la correcta utilización de los principios clásicos del derecho ambiental, así como de los emergentes (in dubio pro natura, in dubio pro aqua y no regresión) y la flexibilización de los institutos procesales clásicos con el fin de adaptarlos a las necesidades y vicisitudes propias de la materia ambiental.
\end{abstract}

Palabras clave: Cortes Latinoamericanas; Jurisprudencia; Derecho ambiental.

Resumo: É objeto de análise deste artigo os julgamentos de matérias ambientais em tribunais superiores de países como Argentina, Brasil, Colômbia, México e Costa Rica. Os acórdãos analisados analisaram as últimas tendências da Justiça Ecológica a nível regional, entre elas: a mudança do paradigma jurídico que governa a relação homem-natureza; o papel preponderante do direito internacional dos direitos humanos e do direito constitucional na proteção ambiental; a aplicação da abordagem baseada nos direitos e a ecologização dos direitos humanos; o uso correto dos princípios clássicos do direito ambiental, bem como dos emergentes (in dubio pro natura, in dubio pro aqua e não regressão), e a flexibilização dos institutos processuais clássicos para adaptá-los às próprias necessidades e vicissitudes da questão ambiental.

Palavras-chave: Cortes latino-americanas; Jurisprudência; Direito ambiental.

$1 \quad$ Coordinador de la Maestría en Derecho Ambiental de la Universidad de Costa Rica. Profesor de la Facultad de Derecho de la Universidad de Costa Rica y de las Maestrías en Derecho Ambiental y Derecho Público del Sistema de Estudios de Posgrados de la Universidad de Costa Rica. Miembro de la Comisión de Derecho Ambiental de la Unión Internacional para la Conservación de la Naturaleza (UICN) y corresponsal nacional del Centré International de Droit Comparé de I'Environnement (CIDCE). Correo: mariopenachacon@gmail.com 
Abstract: The object of analysis of this article is the judgements of environmental matters in higher courts of countries such as Argentina, Brazil Columbia, Mexico and Costa Rica. The accords analyzed are focused on the latest trends in Ecological Justice at regional level, including: the shift of legal paradigm that governs the relationship between humans and nature; the predominant role of international human rights and constitutional rights in environmental protection; the application of the human rights-based approach, and the ecologization of human rights; the correct use of the classical principles of the environmental result, as well as emerging ones, and the flexibilities of the classical procedural institutes for adapting them to the needs and vicissitudes of the environmental question.

Keywords: Latin American courts; Jurisprudence; Environmental law.

\section{INTRODUÇÃO}

El fenómeno de la ecologización del derecho, especialmente de los derechos humanos, empieza a permear las altas cortes latinoamericanas. Prueba de ello son las sentencias de Argentina, Brasil, Colombia, México y Costa Rica, objeto de análisis del presente artículo.

En estos países es posible observar un verdadero cambio en el abordaje de la relación jurídica entre el ser humano y la naturaleza, ambos destinatarios de protección constitucional y convencional.

\section{ARGENTINA}

En primer orden, la Corte Suprema de Justicia de Argentina, a partir de la sentencia "La Pampa, Provincia de c. Mendoza, Provincia de s/ uso de aguas" del 01 de diciembre de 2017 (Cita AR/ JUR/84781/2017), rompió con el modelo antropocéntrico imperante en la gestión del recurso hídrico, introduciendo un nuevo paradigma jurídico de carácter ecocéntrico o sistémico.

En tal sentido, la CSJ dispuso:

La regulación jurídica del agua se ha basado en un modelo antropocéntrico, que ha sido puramente dominial al tener en cuenta la utilidad privada que una persona puede obtener de ella o bien en función de la utilidad pública identificada con el Estado. Esta visión [...] ha cambiado sustancialmente en los últimos años. El paradigma jurídico que ordena la regulación del agua es ecocéntrico, o sistémico, y no tiene en cuenta solamente los intereses privados o estaduales, sino los del mismo sistema, como bien lo establece la Ley General del Ambiente. El ambiente no es para la Constitución Nacional un objeto destinado al exclusivo servicio del hombre, apropiable en función de sus necesidades y de la tecnología disponible, tal como aquello que responde a la voluntad de un sujeto que es su propietario. Ello surge de la Constitución Nacional (art. 41), que al proteger al ambiente permite afirmar la existencia de deberes positivos, es decir, hacer obras en defensa del ambiente.

Esta misma Corte, en la sentencia "Majul, Julio J. c. Municipalidad de Pueblo General Belgrano y otros s/ acción de amparo ambiental" del 11 de julio de 2019 (AR/JUR/22384/2019), ratificó el 
paradigma jurídico ecocéntrico/sistémico, esta vez aplicado a ecosistemas de humedal, destacando además la utilización de principios emergentes del derecho ambiental, específicamente el "in dubio pro natura", extraído de la Declaración de la Unión Internacional para la Conservación de la Naturaleza (UICN) sobre Estado de Derecho en materia ambiental de Río de Janeiro, 2016; así como el principio "in dubio pro aqua", plasmado en el $8^{\circ}$ Foro Mundial del Agua, Brasilia, en la Declaración de Jueces sobre Justicia del Agua, 2018, de Naciones Unidas y la UICN.

En la sentencia "Barrick Exploraciones Argentina S.A. y c. Estado Nacional s/ acción declarativa de inconstitucionalidad" del 4 de junio de 2019, la Corte Suprema rechazó demanda de inconstitucionalidad contra la Ley de Preservación de Glaciares. En ese sentido, la Corte dispuso que:

"cuando existen derechos de incidencia colectiva atinentes a la protección del ambiente -que involucran, en el caso de los glaciares, la posibilidad de estar afectando el acceso de grandes grupos de población al recurso estratégico del agua- se debe considerar de manera sistémica la protección de los ecosistemas y la biodiversidad", advirtiendo que "la norma impugnada resalta la función de los glaciares y del ambiente periglaciar como reserva de agua y que al aprobar dicha norma, el Congreso conectó los efectos de ciertos procesos extractivos -más específicamente, la posible incidencia de la minería a gran escala en ciertas regiones del país- con la preservación y conservación de los glaciares como "reservas estratégicas" proveedoras de agua para el planeta, según el artículo $1^{\circ}$ de esa ley". La Corte concluyó que: "la lectura propuesta se inscribe en el consenso internacional que aprobó el Acuerdo de París en 2015, ratificado por la República Argentina en 2016, sobre calentamiento climático.

\section{MÉXICO}

La Primera Sala de la Suprema Corte de Justicia de México, en la resolución del 14 de noviembre de 2018, amparo en revisión 307/2016, sobre afectaciones ambientales al ecosistema de humedal denominado "Laguna del Carpintero", y citando la Opinión Consultiva OC-23-17 de la Corte Interamericana de Derechos Humanos, reconoció la doble dimensión del derecho humano a un ambiente sano: una objetiva o ecologista, que protege al medio ambiente como un bien jurídico, que atiende a la defensa y restauración de la naturaleza y sus recursos independientemente de los efectos en el ser humano; y otra subjetiva o antropocéntrica, conforme a la cual la protección de este derecho es una garantía para la realización y vigencia de los demás derechos reconocidos en favor de la persona.

La Suprema Corte señaló el carácter de derecho autónomo del derecho al ambiente sano y sus connotaciones tanto colectivas como individuales. Además, la sentencia reconoció los principios clásicos del derecho ambiental, así como los emergentes: in dubio pro natura y no regresión, llegando a la conclusión de la necesidad de flexibilizar las reglas del juicio de amparo, entre ellas los institutos 
procesales de interés legítimo, la relatividad de las sentencias y la inversión de la carga de la prueba, este último, fundamentado en el Acuerdo Regional sobre el Acceso a la información, la Participación Pública y el Acceso a la Justicia en Asuntos Ambientales en América Latina y el Caribe (Acuerdo de Escazú), a efecto de convertir el juicio de amparo en un mecanismo procesal efectivo para la protección constitucional del ambiente ante el riesgo de su afectación y su reparación integral.

Por su parte, en la reciente resolución del 15 de enero de 2020, al resolver el amparo en revisión 610/2019, la Segunda Sala de la Corte Suprema de Justicia de México declaró que el incremento en los niveles de etanol en las gasolinas resulta contrario al derecho humano a un medio ambiente sano, específicamente al principio precautorio; ello debido a encontrarse en debate la magnitud de los posibles daños a la calidad del aire que podría producir el empleo del etanol para oxigenar los combustibles.

En dicha sentencia, la Suprema Corte Suprema enfatizó que los posibles beneficios económicos de abaratar los precios de los combustibles deben ser ponderados y confrontados contra los potenciales riesgos para el medio ambiente y las obligaciones estatales de reducir las emisiones de gases de efecto invernadero y combatir el cambio climático.

\section{COLOMBIA.}

Como es bien sabido, la Corte Constitucional de Colombia en la sentencia T-622/16, del 10 de noviembre de 2016 declaró al río Atrato como sujeto de derechos, mientras que la Suprema Corte de Justicia, Sala de Casación Laboral en la resolución STC 4360-2018, del 05 de abril de 2018, hizo lo mismo con la Amazonía; ambas sentencias han sido objeto de amplia difusión y estudio.

Ahora bien, la Corte Constitucional en la sentencia C-045-19 del 06 de febrero de 2019, declaró inconstitucional la práctica de la caza deportiva disponiendo al efecto que:

El interés superior de protección del ambiente, y de la fauna como parte de este, obliga a la protección de los animales frente al padecimiento, el maltrato y la crueldad. Por consiguiente, la autorización legal de la caza deportiva, al estar orientada exclusivamente a la recreación -lo cual la distingue de otros tipos de caza-, se fundamenta en una aproximación que no considera a los animales como parte del ambiente que debe ser protegido constitucionalmente, sino como recurso disponible para la realización de fines recreacionales particulares del ser humano, sin otra finalidad que su realización misma. En estas condiciones, la caza deportiva es contraria al derecho al ambiente sano y a la obligación de que la educación está orientada, entre otros fines, a la protección del ambiente (arts. 67 y 79 C.P.). Las disposiciones demandadas también vulneran las normas superiores que obligan a diferentes autoridades administrativas a defender el ambiente y la adecuada conservación y planeación del mismo (arts. 80, 277.4, 300.2 y 317 C.P.), exceden los límites constitucionales del derecho a la propiedad (art. 58 C.P.) y la libre iniciativa privada (art. 33 C.P.). 
De esta forma, al amparo del derecho fundamental al ambiente sano, la fauna es destinataria de protección constitucional, poseyendo garantías y beneficios que limitan la actuación del ser humano y le imponen deberes de cuidado frente a ellos.

\section{BRASIL}

Por su parte, el Superior Tribunal de Justicia de Brasil, en la resolución de del 21 de marzo de 2019 (proceso REsp 1.797.175 / SP), en un caso sobre custodia de un loro que había vivido en cautiverio durante 23 años con la persona que lo mantuvo en su residencia, ordenó una serie de medidas de cumplimiento periódico para garantizar su bienestar, entre ellas: la visita semestral de un veterinario especializado en animales salvajes, quien además, deberá enseñar a su guardián el cuidado necesario y apropiado para el ave; así como una inspección anual de verificación de las condiciones del recinto y del animal por parte del Instituto Brasileño de Medio Ambiente y Recursos Naturales Renovables (IBAMA), cuyas recomendaciones serán de obligado acatamiento para su guardián.

Si bien, las medidas ordenadas por el STJ de Brasil no difieren de otras tomadas anteriormente para casos similares sobre guardia de animales silvestres, los razonamientos jurídicos utilizados para motivar la sentencia sí son inéditos. Siguiendo el análisis realizado por los juristas brasileños Sarlet y Fensterseifer, es posible señalar los aspectos más relevantes de la sentencia de rito:

1. Reconocimiento de la dimensión ecológica del principio de dignidad de la persona humana derivado del estado actual de desarrollo a nivel internacional del derecho humano al ambiente (entre otros, la OC-23-17 de la Corte IDH) y del derecho constitucional fundamental a vivir en un ambiente sano y equilibrado (artículo 225 de la Constitución Federal);

2. Redimensionamiento de la relación entre ser humano y naturaleza a partir de un nuevo marco jurídico biocéntrico, reconociendo expresamente la relación de interdependencia entre los seres humanos y la naturaleza, rechazando la relación de dominación humana sobre los "otros seres de la comunidad planetaria";

3. Reconocimiento de la dignidad y el valor intrínseco del animal no humano y la naturaleza, incluido, en el caso de los animales no humanos, como miembros de la misma "comunidad moral compartida con seres humanos";

4. Rechazo del tratamiento legal-civil de los animales no humanos como simples "cosas", señalando la incongruencia entre el régimen legal de los animales no humanos en el Código Civil de 2002 y la Constitución (artículo 225);

5. La utilización de la expresión "guardia", evitando así hablar de "posesión" de un animal no humano. 


\section{COSTA RICA}

Por último, corresponde el turno a la Sala Constitucional de la Corte Suprema de Costa Rica, la cual, en el voto 2019-17397 del 11 de setiembre de 2019, declaró parcialmente con lugar una acción de inconstitucionalidad planteada contra el artículo 18 de la Ley Forestal que autorizó el aprovechamiento excepcional de agua potable para consumo humano en terrenos del Patrimonio Natural del Estado, señalando lo siguiente:

El derecho al ambiente no puede ceder ante consideraciones de índole económica, por tratarse de un derecho no patrimonial y de indudable importancia no solo para los habitantes del país actualmente, sino también para los sucesivos.

Con relación al supuesto conflicto entre el derecho humano al ambiente sano y equilibrado y el derecho humano al agua potable, en el citado voto, la Sala Constitucional aplicó el enfoque basado en derechos en el ámbito ambiental y de ecologización de los derechos humanos, al disponer:

Recordemos que esta Sala ha mencionado que los Tribunales Constitucionales no deben actuar aislados de su realidad histórica, política y sociocultural y más aún, que están obligados a valorar el derecho de la Constitución como una unidad sistémica de valores, principios y normas, que, en consecuencia, deben ser interpretados y aplicados no aisladamente, sino con criterio sistemático, en armonía unos con otros, los cuales resultan así, indivisibles e interdependientes (véase sentencia número 2012-016074 de las 16:00 horas del 21 de noviembre de 2012). De esta forma, ambos derechos fundamentales (derecho al agua y derecho a un ambiente sano y ecológicamente equilibrado) deberán de interpretarse de forma armónica. Por eso, en la ley cuestionada se establece la posibilidad de aprovechar el agua de los terrenos del patrimonio natural del Estado siempre y cuando se cumpla con una serie de requisitos tendientes a respetar el ambiente. Así, el objetivo de la ley es garantizar un uso racional de los recursos y para evitar la afectación de los recursos existentes en el patrimonio natural del Estado. Así, como ya se indicó en los considerandos anteriores, el artículo 50 constitucional reconoce de forma expresa el derecho de todos los habitantes del país a disfrutar de un medio ambiente saludable y en perfecto equilibrio. Ese derecho es garantía fundamental para la protección de la vida y la salud pública. En apoyo de lo anterior este Tribunal ha recurrido a la utilización de la noción de "calidad ambiental" como un parámetro, precisamente, de la calidad de vida de las personas, que se conjuga con otros elementos tales como la salud, la alimentación, el trabajo y la vivienda, haciendo referencia a que toda persona tiene derecho a hacer uso del ambiente para su propio desarrollo pero no de manera ilimitada, ya que, también, existe un deber de protección y preservación del medio ambiente para las generaciones presentes y futuras -principio de desarrollo sostenible ${ }^{2}$. 
Esta misma Sala, en el voto número 2019-24513 del 06 de diciembre de 2019, aplicando el principio precautorio, tuteló de forma conjunta y sinérgica los derechos humanos a la vida y salud de las personas, medio ambiente, seguridad alimentaria y biodiversidad, al prohibir el uso de plaguicidas y productos químicos industriales que contengan "neonicotinoides", por sus posibles daños sobre la salud pública y la biodiversidad - incluyendo a las poblaciones de abejas melíferas-.

En ese sentido dispuso:

Recuérdese que esta jurisdicción está llamada -constitucionalmente- a tutelar los derechos fundamentales de las personas; entre ellos, además de la vida y la salud de las personas, el medio ambiente, la seguridad alimentaria y la biodiversidad, elementos que según se ha podido apreciar de los autos, podrían estar en riesgo por el uso de neonicotinoides. La Administración Central no se encuentra exenta de responsabilidad, pues también está en el deber de actuar en forma eficaz y anticipada, para evitar posibles eventos que degraden el medio ambiente y comprometan su sostenibilidad. En la especie, se ha podido observar que los plaguicidas y productos químicos industriales denunciados por el recurrente (neonicotinoides) son sustancias que podrían causar daños a la biodiversidad, incluyendo a las poblaciones de abejas melíferas, así como a la salud pública. El Ministerio de Agricultura y Ganadería enfatiza en este amparo que, en el caso específico de los neonicotinoides, no cuentan con certeza científica del daño alegado por el recurrente. Sin embargo, debe recordársele a dicha cartera, la obligatoria aplicación de los principios que rigen la materia ambiental; entre ellos, los principios preventivo y precautorio, desarrollados líneas arriba. De modo tal, que no basta con afirmar que, actualmente, no se cuenta con certeza científica para demostrar el daño denunciado por el promovente, ya que como se ha visto en este recurso de amparo, existen múltiples criterios técnicos nacionales, decisiones y acuerdos internacionales, así como estudios científicos documentados en materia ambiental, que arrojan el potencial riesgo en la utilización de tales plaguicidas y productos químicos industriales denunciados por el recurrente (neonicotinoides). Precisamente, el principio precautorio, contemplado tanto en el ordinal 11 , de la Ley de Biodiversidad ( $\mathrm{N}^{\circ} 7788$ ), como en el principio 15, de la Declaración de Río, aplica cuando existe falta de certeza científica sobre los riesgos y sus impactos, es decir, cuando no existe certeza si una sustancia causa un grave impacto ambiental intolerable, pero existe información suficiente que se ha evaluado y el resultado es la falta de certeza, como justamente ocurre en este caso de los neonicotinoides. En consecuencia, estima este Tribunal que, en aplicación del principio precautorio vigente en materia ambiental, así como diversos instrumentos internacionales que regulan esta rama (entre ellos, la Declaración de Río y el Convenio de Rotterdam para la Aplicación del Procedimiento de Consentimiento Fundamentado Previo a Ciertos Plaguicidas y Productos Químicos Peligrosos Objeto del Comercio Internacional), sin dejar atrás la tutela especial que indican los artículos 21 y 50, de la Constitución Política, la cual esta Sala está llamada a proteger, lo que corresponde en el sub lite es acoger el recurso de amparo incoado, con las consecuencias que se dirán en la parte dispositiva de la sentencia.

\section{CONSIDERACIONES FINALES}

Las sentencias antes analizadas muestran las últimas tendencias de la Justicia Ecológica a nivel regional, entre ellas: el cambio en el paradigma jurídico que rige la relación hombre-naturaleza; el 
papel preponderante del derecho internacional de los derechos humanos y del derecho constitucional en la protección ambiental; aplicación del enfoque basado en derechos y de ecologización de los derechos humanos; la correcta utilización de los principios clásicos del derecho ambiental, así como de los emergentes (in dubio pro natura, in dubio pro aqua y no regresión) y la flexibilización de institutos procesales clásicos con el fin de adaptarlos a las necesidades y vicisitudes propias de la materia ambiental.

A través de dichas sentencias, las altas cortes de Argentina, México, Brasil, Colombia y Costa Rica dieron un paso adelante hacia el fortalecimiento y consolidación del Estado de derecho ambiental.

\section{REFERENCIAS}

Peña Chacón, M., "Enfoque de derechos en el ámbito ambiental y ecologización de los derechos humanos", en Revista del Posgrado en Derecho de la Universidad de Costa Rica, disponible en: https://derecho.ucr.ac.cr/Posgrado/derechoambiental/enfoque-de-derechos-en-el-ambito-ambiental-y-ecologizacion-de-los-derechos-humanos/ (consultado el 29 de enero de 2020)

Peña Chacón, M, Justicia Ecológica del siglo XXI, Revista de Derecho Ambiental número 57, enero - marzo 2019, Thomson Reuters, Argentina.

Pinto, M., "Los derechos de la naturaleza y de los animales. De los debates dogmáticos a las anomalías Jurisprudenciales", en Revista de Derecho Ambiental, edición 15 aniversario, Abeledo Perrot, 2019, Argentina.

Sarlet, I., Fensterseifer, T., "STJ, A dimensão ecológica da dignidade e diretos do animal não humano", en CONJUR, Boletín de noticias, disponible en: https://www.conjur.com.br/2019-mai-10/direitos-fundamentais-stj-dimensao-ecologicadignidade-direitos-animal-nao-humano (consultado el 29 de enero de 2020)

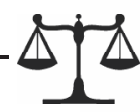

